\title{
EKSPATRIAT DAN INDUSTRI LINTAS NEGARA
}

\author{
MOCHAMMAD AL MUSADIEQ \\ Fakultas Ilmu Administrasi (FIA) Universitas Brawijaya Malang \\ E-mail: mmusadieq@yahoo.co.id
}

\begin{abstract}
ABSTRAK
Riset ini bertujuan untuk menggambarkan karakteristik demografi dan shock culture yang dialami oleh para ekspatriat yang ditugaskan di Malang dan Surabaya. Penelitian ini telah menganalisis 30 responden. Berdasarkan hasil analisis deskriptif dengan menggunakan tabel distribusi frekuensi diperoleh gambaran bahwa mayoritas responden berkedudukan sebagai representatif, berusia antara 30-40 tahun, berkebangsaan Jepang, berpendidikan sarjana SI, berjenis kelamin laki-laki, telah menikah, memiliki anak dan anak-anak mereka ikut ke Indonesia, merupakan tugas pertama mereka keluar negeri, dan mereka tinggal di Indonesia untuk jangka waktu 1-2 tahun. Hasil analisis reskriptif juga memberikan gambaran bahwa mereka mampu beradaptasi dengan budaya lokal Indonesia.
\end{abstract}

Kata kunci: ekspariat, karakteristik demografi, shock culture

\begin{abstract}
This research aims to describe demography characteristics and shock culture of expatriate being assigned in Malang and Surabaya. The research analysis toward 30 respondents by using table of frequency distribution resulted that majority of respondents are representative, age between 30 to 40 years old, Japanese, bachelor, male, married, have kids, accompanied by their kids, first overseas assignment, and stay in Indonesia for 1 to 2 years. Moreover the research shows that majority of respondents are able to cope with cultural differences. They do not have shock culture problems.
\end{abstract}

Key words: expatriate, demography characteristics, shock culture

\section{PENDAHULUAN}

Menjadi ekspatriat adalah suatu peluang sekaligus tantangan. Peluang karena bisa menjadi jembatan emas untuk meniti karir yang lebih baik. Tantangan karena bertugas keluar negeri penuh risiko dengan tingkat kegagalan yang cukup tinggi, yang penyebab utamanya adalah apa yang disebut 'shock culture'. Calon ekspatriat harus mempertimbangkan dua faktor sebelum bertugas ke luar negeri, yaitu: kemampuan adaptasi budaya dan filosofi organisasi atas penugasan ke luar negeri (Copeland and Griggs, 1985).

Kemampuan adaptasi budaya mengandung pengertian pada kecakapan yang dimiliki seseorang yang membuatnya mampu menyesuaikan diri dengan budaya asing. Riset yang dilakukan atas kemampuan para ekspatriat menunjukkan secara jelas, bahwa keberhasilan pelaksanaan tugas ekspatriat tergantung pada pemilikan kecakapan tertentu, yaitu: kecakapan pribadi, kecakapan bergaul, dan kecakapan persepsi (Mendenhall and Oddou, 1985). Kecakapan pribadi menyangkut kematangan mental dan emosional seseorang. Seseorang yang memiliki kecakapan pribadi akan lebih mudah beradaptasi. Kecakapan bergaul adalah kemampuan seseorang untuk berinteraksi dengan orang lain secara efektif, khususnya dengan orang asing (Harris and Moran,1979). Kemampuan bergaul ini sangat diperlukan dalam adaptasi lintas budaya. Kecakapan persepsi berhubungan dengan suatu proses kognitif yang membantu seseorang dalam memahami mengapa orang asing berperilaku tertentu. Karakteristik adalah ciri-ciri yang melekat pada diri seseorang. Sedangkan yang dimaksud dengan demografi adalah aspek demografis. Oleh sebab itu karakteristik demografi ekspatriat adalah ciri-ciri aspek demografis yang melekat pada seorang ekspatriat. Menurut beberapa ahli karakteristik demografi ekspatriat meliputi usia, jenis kelamin, tingkat pendidikan, pasangan (spouse), jumlah anak, penugasan internasional sebelumnya, masa kerja, dan status perkawinan (Shafer and Harrison, 1998).

Tujuan penelitian ini adalah untuk mengungkapkan bagaimana gambaran demografis para ekspatriat dan bagaimana gambaran kejutan budaya yang mereka alami ketika beradaptasi dengan budaya lokal Indonesia. Dari penelitian ini diharapkan memberi informasi tentang para ekspatriat yang memegang peranan kunci dalam pengembangan industri yang bersifat lintas negara, 
khususnya para ekspatriat yang bertugas di Malang dan Surabaya.

\section{METODE}

Penelitian ini mengambil lokasi Kota Malang dan Surabaya, karena berdasarkan informasi Dinas Tenaga Kerja Kota Malang dan Surabaya terdapat cukup banyak ekspatriat yang ada di kedua kota tersebut, walaupun jumlah pastinya sulit dipastikan, karena mereka datang dan pergi.

Sebuah daftar pertanyaan telah dikembangkan untuk menjaring data karakteristik demografis responden dan juga untuk menjaring kemampuan adaptasi budaya responden dengan 5 pilihan jawaban, yaitu: sangat tidak setuju, tidak setuju, netral, setuju, sangat setuju. Variabel pertama yang diteliti adalah "karakteristik demografis ekspatriat" dengan indikator meliputi usia, jenis kelamin, tingkat pendidikan, pasangan (spouse), jumlah anak, penugasan internasional sebelumnya, masa kerja, dan status perkawinan. Sementara variabel kedua adalah "kemampuan adaptasi budaya ekspatriat" yang berupa kecakapan pribadi, kecakapan bergaul, dan kecakapan persepsi, dengan indikator meliputi kemudahan tidur, kepercayaan pada orang Indonesia, mudah konsentrasi, tidak tertekan, tetap terkendali, tidak mudah tersinggung, mau makan dan minuman lokal, merasa nyaman dalam bekerja. Data dianalisis secara deskriptif dengan menggunakan tabel distribusi frekuensi.

Tahapan selanjutnya yang dilakukan untuk mengumpulkan data adalah berusaha mengumpulkan data tentang keberadaan responden. Berdasarkan data yang diberikan oleh pihak terkait, dicoba untuk menghubungi responden. Namun ternyata banyak di antara ekspatriat tersebut sudah tidak berada di Malang atau Surabaya pada saat pengumpulan data dilakukan. Dalam proses mengumpulkan data tentang responden ini, juga ditemui beberapa perusahaan yang dirujuk, ternyata sudah tidak beroperasi lagi. Sehingga dalam dua bulan pertama penelitian, hanya dapat dijumpai satu orang responden saja, yaitu seorang ekspatriat dari Selandia Baru. Responden pertama ini bersedia memberikan koreksi atas isi kuesioner dan memberikan saran-saran perbaikan terhadap butir-butir pertanyaan dalam kuesioner. Salah satu rekomendasinya adalah penghapusan nama dan jabatan responden. Selanjutnya beberapa responden Australia juga menyatakan keberatannya mengisi kuesioner yang terkait dengan data pribadi. Selanjutnya dari wawancara yang dilakukan terhadap responden lainnya, dilakukan klarifikasi data apa saja yang dapat diungkap dalam laporan penelitian, dan data mana yang diminta dijaga kerahasiaannya.
Jumlah ekspatriat yang akhirnya bersedia menjadi responden dalam penelitian ini adalah 30 orang.

\section{HASIL DAN PEMBAHASAN}

\section{Gambaran Karakteristik Demografi Ekspatriat}

Dari kuesioner yang diberikan dan wawancara yang dilakukan terhadap 30 responden, diperoleh data tentang karakteristik demografi ekspatriat yang meliputi jabatan, umur, kebangsaan, tingkat pendidikan, jenis kelamin, status perkawinan, pendamping, anak-anak, penugasan internasional sebelumnya dan lama tinggal di Indonesia sebagai mana nampak pada Tabel 1 sampai Tabel 12 berikut ini.

Tabel 1. Distribusi Responden Berdasarkan Jabatan

\begin{tabular}{lc}
\hline \multicolumn{1}{c}{ Jabatan } & Persentase (\%) \\
\hline Representative & 23,33 \\
Director & 10,00 \\
Senior staf & 20,00 \\
Manager & 10,00 \\
Lain-lain & 6,67 \\
Tidak merespon & 30,00 \\
\hline Total & 100,00 \\
\hline
\end{tabular}

Berdasarkan data pada Tabel 1, jabatan responden yang terbanyak adalah Representative, kemudian Senior Staf, Direktur dan Manager.

Tabel 2. Distribusi Responden Berdasarkan Usia

\begin{tabular}{lc}
\hline \multicolumn{1}{c}{ Usia } & Persentase (\%) \\
\hline 29 tahun ke bawah & 10,00 \\
$30-40$ & 43,33 \\
41 tahun keatas & 46,67 \\
Total & 100,00 \\
\hline
\end{tabular}

Berdasarkan data pada Tabel 2, usia responden yang terbanyak adalah 41 tahun ke atas, kemudian antara 30-40 tahun, dan sisanya berusia 29 tahun ke bawah.

Tabel 3. Distribusi Responden Berdasarkan Kebangsaan

\begin{tabular}{lc}
\hline \multicolumn{1}{c}{ Kebangsaan } & Persentase (\%) \\
\hline Jepang & 36,67 \\
Australia & 23,33 \\
Korea & 13,33 \\
New Zealand & 10,00 \\
Inggris & 3,33 \\
Jerman & 3,33 \\
Philipina & 3,33 \\
India & 3,33 \\
Kanada & 3,33 \\
\hline Total & 100,00 \\
\hline
\end{tabular}


Berdasarkan data pada Tabel 3, kebangsaan responden yang terbanyak adalah Jepang, kemudian Australia, Korea dan New Zealand.

Tabel 4. Distribusi Responden Berdasarkan Tingkat Pendidikan

\begin{tabular}{llc}
\hline No. & \multicolumn{1}{c}{ Tingkat Pendidikan } & Persentase (\%) \\
\hline 1 & Bachelor (Sarjana) & 90 \\
2 & SMU \& Certificate Diplomas & 6,67 \\
3 & Masters & 3,33 \\
\hline \multicolumn{2}{l}{ Total } & 100,00 \\
\hline
\end{tabular}

Berdasarkan data pada Tabel 4, pendidikan responden yang terbanyak adalah Sarjana, lalu SMU, baru kemudian Magister.

Tabel 5. Distribusi Responden Berdasarkan Jenis Kelamin

\begin{tabular}{lc}
\hline \multicolumn{1}{c}{ Jenis Kelamin } & Persentase (\%) \\
\hline Pria & 90,00 \\
Wanita & 10,00 \\
\hline Total & 100,00 \\
\hline
\end{tabular}

Berdasarkan data pada Tabel 5, mayoritas responden berjenis kelamin pria.

Tabel 6. Distribusi Responden Berdasarkan Status Perkawinan

\begin{tabular}{lc}
\hline \multicolumn{1}{c}{ Status Perkawinan } & Persentase (\%) \\
\hline Sudah Kawin & 76,67 \\
Belum Kawin & 23,33 \\
\hline Total & 100,00 \\
\hline
\end{tabular}

Berdasarkan data pada Tabel 6, sebagian besar responden berstatus sudah kawin.

Tabel 7. Distribusi Responden Berdasarkan Pendamping (spouse)

\begin{tabular}{lc}
\hline \multicolumn{1}{c}{ Pendamping } & Persentase (\%) \\
\hline Tidak Ada Pendamping & 43,33 \\
Ada Pendamping & 56,67 \\
\hline Total & 100,00 \\
\hline
\end{tabular}

Berdasarkan data pada Tabel 7, lebih dari setengah responden ternyata didampingi oleh pasangan (spouse).

Tabel 8. Distribusi Responden Berdasarkan Ada Tidaknya Anak

\begin{tabular}{lc}
\hline \multicolumn{1}{c}{ Anak } & Persentase (\%) \\
\hline Tidak Mempunyai Anak & 36,67 \\
Mempunyai Anak & 63,33 \\
\hline Total & 100,00 \\
\hline
\end{tabular}

Berdasarkan data pada Tabel 8 di atas, sebagian besar responden sudah mempunyai anak.

Tabel 9. Distribusi Responden Berdasarkan Keikutsertaan Anak

\begin{tabular}{lc}
\hline \multicolumn{1}{c}{ Keikutsertaan Anak } & Persentase (\%) \\
\hline Anak Tidak Ikut di Indonesia & 20 \\
Anak ikut di Indonesia & 43,33 \\
\hline Total & 63,33 \\
\hline
\end{tabular}

Berdasarkan data pada Tabel 9, sebagian responden membawa anak-anaknya tinggal di Indonesia.

Tabel 10. Distribusi Responden Berdasarkan Penugasan Internasional

\begin{tabular}{lc}
\hline Penugasan Internasional & Persentase (\%) \\
\hline Pernah & 20,00 \\
Tidak Pernah & 80,00 \\
\hline Total & 100,00 \\
\hline
\end{tabular}

Berdasarkan data pada Tabel 10, mayoritas responden tidak pernah memperoleh penugasan internasional sebelumnya. Hanya 6 orang responden menyatakan pernah menjalankan penugasan internasional sebelumnya. Dari 6 orang responden tersebut, dapat dideskripsikan negara-negara tempat bertugas sebelumnya serta masa penugasannya, sebagaimana nampak pada Tabel 11 di bawah ini.

Tabel 11. Distribusi Responden berdasarkan Penugasan Sebelumnya

\begin{tabular}{l}
\hline \multicolumn{1}{c}{ Penugasan Internasional } \\
\hline Holland selama 1 tahun \\
Bangladesh, India dan Vietnam selama 2 tahun \\
Spain selama 1 tahun, dan checz Republik selama 6 bulan \\
Japan selama 3 Tahun 10 bulan; Macau selama 3 tahun 8 bulan \\
Hongkong selama 4 tahun dan Thailand selama 1 tahun \\
India selama 6 tahun 6 bulan \\
Ethiopia selama 6 bulan dan England selama 6 bulan \\
\hline
\end{tabular}

Berdasarkan data pada Tabel 11, negara tempat bertugas sebelumnya bervariasi, sedangkan masa tugasnya dari 6 bulan sampai dengan 6 tahun setengah.

Tabel 12. Distribusi Responden Berdasarkan Lama Tinggal di Indonesia

\begin{tabular}{lc}
\hline \multicolumn{1}{c}{ Lama Tinggal } & Persentase (\%) \\
\hline 1 tahun kebawah & 26,67 \\
Di atas 1-2 tahun & 30,00 \\
Di atas 2-3 tahun & 13,33 \\
Di atas 3-4 tahun & 6,67 \\
Di atas 4 tahun & 23,33 \\
\hline Total & \\
\hline
\end{tabular}


Berdasarkan data pada Tabel 12, lama tinggal responden di Indonesia sebagian besar di atas 1 tahun sampai dengan 2 tahun, kemudin 1 tahun ke bawah, dan di atas 4 tahun.

Dari hasil analisis deskriptif dengan menggunakan tabel distribusi frekuensi, mulai Tabel 1 sampai dengan Tabel 12, diperoleh gambaran bahwa mayoritas ekspatriat di Kota Surabaya dan Malang memiliki karakteristik demografis sebagai berikut: bertugas sebagai representative, berusia antara 30-40 tahun, berasal dari Jepang, berpendidikan S1, berjenis kelamin pria, sudah kawin, memiliki pendamping (spouse), memiliki anak, membawa anak ikut serta ke Indonesia, tidak pernah bertugas ke luar negeri sebelumnya, dan sudah bertugas di Indonesia selama 1-2 tahun.

\section{Gambaran Kejutan Budaya Ekspatriat}

Gambaran kejutan budaya yang dialami oleh para ekspatriat dapat dilihat pada Tabel 13 berikut ini.

Tabel 13. Kejutan Budaya yang Dialami Ekspatriat

\begin{tabular}{lcl}
\hline \multicolumn{1}{c}{ Item Pertanyaan } & $\begin{array}{c}\text { Skor } \\
\text { rata-rata }\end{array}$ & Interpretasi \\
\hline $\begin{array}{l}\text { Saya menderita sulit tidur yang } \\
\text { mana jarang saya rasakan ketika di }\end{array}$ & 1,80 & Rendah \\
negara saya sendiri & & \\
$\begin{array}{l}\text { Saya tidak percaya orang Indonesia } \\
\text { karena saya takut dicurangi }\end{array}$ & 2,03 & Rendah \\
$\begin{array}{l}\text { Saya merasa sulit berkonsentrasi } \\
\text { ketika bekerja di Indonesia }\end{array}$ & 1,47 & Rendah sekali \\
$\begin{array}{l}\text { Saya merasa ada tambahan strees } \\
\text { ketika sedang berinteraksi dengan }\end{array}$ & 2,13 & Rendah \\
$\begin{array}{l}\text { orang Indonesia } \\
\text { Saya merasa alergi dengan berbagai } \\
\text { suasana daripada yang saya rasakan } \\
\text { sebelumnya. }\end{array}$ & 1,97 & Rendah \\
$\begin{array}{l}\text { Saya marah atau menggunakan } \\
\text { kata-kata kasar ketika memerintah } \\
\text { orang Indonesia }\end{array}$ & 1,80 & Rendah \\
$\begin{array}{l}\text { Saya merasa ragu dengan air } \\
\text { minum, makanan dan lingkungan } \\
\text { orang Indonesia }\end{array}$ & 2,17 & Rendah \\
$\begin{array}{l}\text { Saya merasa tidak terbantu dan } \\
\text { tidak sabar ketika berinteraksi } \\
\text { dengan orang Indonesia } \\
\text { Rata-rata skor secara keseluruhan }\end{array}$ & 1,67 & Rendah sekali \\
\hline & & \\
& & Rendah \\
\hline
\end{tabular}

Berdasarkan data pada Tabel 13, diperoleh gambaran bahwa mayoritas ekspatriat di Kota Surabaya dan Malang tidak mengalami kesulitan dalam melakukan adaptasi budaya, dengan indikasi kejutan budaya yang dialami rendah dan sangat rendah. Mereka tidak merasa sulit tidur, tidak takut dicurangi oleh orang Indonesia, tidak memiliki tambahan stress ketika berinteraksi dengan orang Indonesia, tidak merasa alergi dengan berbagai suasana, hampir tidak pernah menggunakan kata- kata yang kasar dan marah, juga hampir tidak pernah merasa ragu dengan air minum, makanan dan lingkungan. Selanjutnya mereka merasa masih terbantu dan sabar jika berinteraksi dengan orang Indonesia, serta dapat berkonsentrasi dengan baik ketika bekerja di Indonesia.

\section{SIMPULAN}

Penelitian ini berhasil mengungkapkan bahwa mayoritas ekspatriat di Kota Surabaya dan Malang berasal dari Jepang dengan usia relatif masih muda. Kebanyakan dari mereka menjalankan tugas luar negeri yang pertama, sebagai representatif dan membawa keluarga mereka dalam tugas. Penelitian juga mengungkapkan bahwa para ekspatriat tersebut tidak mengalami kesulitan dalam melakukan adaptasi dengan budaya lokal Indonesia. Informasi ini memberikan optimisme bahwa investasi langsung dari manca negara akan tertarik masuk ke Indonesia, karena dari sudut pandang sumberdaya manusia mereka tidak mengalami kesulitan mencari ekspatriat. Temuan ini penting karena berbagai hasil penelitian sebelumnya melaporkan bahwa tingkat kegagalan ekspatriat industri lintas negara cukup tinggi disebabkan kegagalan mereka dalam beradaptasi lintas budaya.

\section{DAFTAR PUSTAKA}

Blunt, P. \& Richards, D. 1993. Reading in Management, Organization and Culture in East and Shouthest Asia. NTU Press, Northern Territory University, Darwin, NT. Australia.

Copeland, L. and Griggs, L. 1985. Going International. Random House, New York.

Harris, P.R. and Moran, R.T. 1979.Managing Cultural Differences, Gulf, Houston Tex.

Harvey, M.G. 1985. The Executive Family : An Overlooked Variable in International Assignments, Columbia Journal of World Business, Spring.

Mendenhall, M. and Oddou, G. 1985. The Dimensions of Expatriate Acculturation: A Review. Academy of Management Review.

Morgan, P.V \& Botrall, P.J. 1988. Trends in International Human Resource Management. Journal of Human Resource Management, Australia, February.

Shaffer, Margaret A. \& Harrison, David. A. 1998. Expatriates' Psychological Withdrawal from International Assignments Work, Nonwork, and FamilyInfluences, Journal Personnel Psychology.

Singarimbun, M. \& Sofian, E. 1995. Metode Penelitian Survei. Jakarta: LP3ES.

Torbiorn, I. 1982. Living Abroad: Personal Adjustment and Personnel Policy in the Overseas Setting. Wiley, New York.

Tung, R.L. 1992. Selection and Training of Personnel for Overseas Assignments. Columbia Journal of World Business. 